\title{
Unlicensed and off-label medicines and prescriptions: A descriptive analysis of the medicines formulary and of the 56,800 prescriptions in a paediatric hospital
}

\author{
Sarah Delmas ${ }^{1}$, Olivier Bourdon ${ }^{1,2}$, Françoise Brion ${ }^{1,2}$, Sonia Prot-Labarthe ${ }^{1,3 *}$ \\ ${ }^{1}$ Department of Pharmacy, Robert-Debré Hospital, Assistance Publique - Hôpitaux de Paris, Paris, France; Sorbonne Paris Cité, Université Paris Descartes, \\ Pharmacie Clinique, France \\ ${ }^{2}$ Sorbonne Paris Cité, Université Paris 13, Laboratoire Educations et Pratiques de Santé, EA 3412, France \\ ${ }^{3}$ Inserm, U1123, ECEVE, Paris
}

\begin{abstract}
Introduction: There are not enough medicines approved for paediatric use. A very large number of prescriptions are unlicensed or off-label in different countries, diseases and patient ages.

Methods: The aim of our retrospective observational study was to analyse the proportion of unlicensed and off-label prescriptions in a paediatric University Hospital Centre (UHC) over a period of six months and to compare this to the alternatives available in the medicines formulary.

Results: Of the 1,865 medicines in the formulary, $8.0 \%$ were approved for paediatric use without age or weight limit and $47.1 \%$ were approved for paediatric use with an age or weight limit. Of the 56,820 prescriptions examined, 30.7\% were off-label and 4.5\% were unlicensed medicines. $53.6 \%$ of the 5,803 patients received at least one unlicensed or off-label prescription. This study has enabled us to identify situations ( 1 to 30 months old, Haematology unit, pantoprazole and folic acid prescription for example), which are more commonly associated with off-label prescribing.

Discussion: Our study is original as it examines in parallel those medicines which are available and the prescriptions which are issued. It has analysed a large number of prescriptions for hospitalised patients in sixteen different specialist departments. Off-label or unlicensed prescribing paediatric use raises a safety and efficacy problem for the treatments given. For this reason it is important to target situations and to produce reference standards which can be used in everyday practice by doctors in order to limit their use of these prescriptions.
\end{abstract}

\section{Introduction}

Children are not "miniature adults" and need appropriate medicines and clinical studies for their illnesses and metabolic, psychological and motor development [1-3]. Many studies have reported a lack of appropriate available medicines because of the small number of clinical studies [4-7]. The primary consequence of this lack of medicines is the practitioners' use of "off-label" prescriptions (outside of their marketing authorisation or MA) and the use of unlicensed medicines (those which do not have MA). These are not incorrect prescriptions and may be the best available solution in a given situation. Although this is common in hospitals, with an off-label use of $18 \%$ to $60 \%$ of prescriptions and unlicensed use of $0 \%$ to $48 \%$ of prescriptions, [811] the same phenomenon is seen in primary care with an off-label prescribing rate of $10 \%$ to $29 \%$ of prescriptions and unlicensed drug prescribing rate of $0 \%$ to $17 \%$ [12-15]. These prescriptions raise the ethical difficulty of the lack of scientifically proven information and expose the child to a risk both of the treatment being ineffective and to a risk of adverse effects [16-19].

Most results available to date are based on small numbers of patients over short periods of time in a specific medical department or only on the proprietary products available. The aim of our study was to analyse the availability of medicines for off-label or unlicensed use (those without MA) and the proportion of prescriptions these accounted for.

\section{Methods}

The Robert-Debré Hospital (AP-HP) is a 475 bed mothers and child UHC (415 paediatric and 60 obstetrics-gynaecology beds) which we will refer to below as the births service for babies in this department (35,000 admissions annually including 9,000 in gynaecology and perinatal medicine).

\section{Analysis of the formulary}

The medicines formulary is the list of medicines approved by the pharmacy available for prescribing to patients. The medicines contained in the formulary were extracted from Copilote ${ }^{\circledR}$ (Savart and Michel, France) on 1 January 2012. The exclusion criteria for medicines

Correspondence to: Sonia Prot-Labarthe, Department of Pharmacy, RobertDebré Hospital, Assistance Publique - Hôpitaux de Paris, Paris, France; Sorbonne Paris Cité, Université Paris Descartes, Pharmacie Clinique, Service de Pharmacie 48 boulevard Sérurier, 75935 Paris Cedex 19, France, Tel: 33 (1) 4003 57 41; Fax: 33(1) 400324 81; E-mail: sonia.prot-labarthe@aphp.fr

Key words: paediatrics, paediatric indication, off-label use, unlicensed use, appropriate pharmaceutical form

Received: March 06, 2016; Accepted: April 18, 2016; Published: April 20, 2016 
Delmas S (2016) Unlicensed and off-label medicines and prescriptions: A descriptive analysis of the medicines formulary and of the 56,800 prescriptions in a paediatric hospital

were dietetic foods for specialist medical purposes, antiseptic agents, aqueous-alcoholic solutions and soaps, sanitary products, catheter locks, gases, diagnostic strips, insulin injection devices, medical gases, parapharmacy creams and suncreams, parental nutrition bags, electrolyte or glucose infusion solutions, transplant preservation solutions, placebos and chorionic gonadotropin.

For each proprietary product we collected the following information: international non-proprietary name (INN), commercial status (approved, with MA, ATU: temporary authorisation for use, HP: hospital preparation), pharmaceutical form, route of administration, anatomical and therapeutic chemical class (ATC) and paediatric status (PI, AL, CI, AD, N, RA, AI, see Table 1). Paediatric status was coded from the Thériaque ${ }^{\circledR}$ database (CNHIM, Paris, 2012) [20].

\section{Analysis of prescriptions}

This was a retrospective observational study. Information on prescriptions was extracted from $\mathrm{PCS}^{\circledR}$ software (IBM, USA). Inclusion criteria were all prescriptions issued at the Robert-Debré Hospital between 1 June and 30 November 2011 for patients under fifteen years old, except for injectable chemotherapies.

The information collected for the prescription analysis included (1) the patient: sex, weight, age on first day of prescription, number of prescriptions and (2) the treatment prescribed: commercial status (MA, ATU, HP or MP - for a named person preparation), INN, ATC class, route, pharmaceutical form, duration, whether or not the prescription was off-label in terms of age and weight limits and whether or not the pharmaceutical form was suitable for patients under six years old.

The protocol was not submitted to an ethics committee for several reasons: the data were extracted entirely anonymously for both prescriptions and the formulary; the large number of prescriptions and presentation of results prevents any patient identification.

We chose to adopt the terms off-label and unlicensed as described by Turner: off-label prescription for prescriptions not approved under their MA in terms of the age, weight, dosage, indication or route of administration (medicines which are contraindicated are deemed to be prescribed off-label); unlicensed preparations for prescriptions of medicines with ATU, HP or named patient basis pharmacy preparations (NBP) [11]. Only age and weight were considered in assessing approval under the MA in our study.

The statistical analysis was performed on Excel $^{\circledR}$ software $\left(\right.$ Microsoft $\left.^{\circledR}, 2002\right)$. Qualitative variables are shown as percentages and quantitative variables as minimum and maximum values with their interquartile ranges.

Table 1. Definition of paediatric statuses from Masseron et al., 2006.

\begin{tabular}{|l|l|}
\hline Acronym & Paediatric status \\
\hline PI & A medicine with a paediatric indication unrestricted to age or weight. \\
\hline AL & A medicine with a paediatric indication with an age limit or weight limit. \\
\hline CI & A medicine which is contraindicated in children. \\
\hline AD & $\begin{array}{l}\text { A medicine whose use is not recommended in children because of an absence } \\
\text { of clinical data. }\end{array}$ \\
\hline N & $\begin{array}{l}\text { Medicines in which the monograph does not contain any paediatric information } \\
\text { ("nothing in the monograph"). }\end{array}$ \\
\hline RA & \begin{tabular}{l} 
Medicines whose use is restricted for adults. \\
\hline AI*
\end{tabular} \\
$\begin{array}{l}\text { Medicines in which the monograph provides information but no paediatric } \\
\text { indication (absence of information). }\end{array}$ \\
\hline
\end{tabular}

*The AI category has been added to the existing classification of Masseron et al, 2006.

\section{$\underline{\text { Results }}$}

The formulary contained 2,459 items, 594 of which were excluded. The formulary analysis was therefore based on 1,865 items for 504 different INN. The inclusion process for prescriptions is described in Figure 1. The 56,820 prescriptions included involved 5,803 patients ( $43.9 \%$ or 2,550 of which were girls) with a total of 7,432 hospital stays. Patient characteristics are shown in Table 2.

A total of $4.5 \%$ of all prescriptions $(2,540)$ were unlicensed and $30.7 \%(17,439)$ of prescriptions were off-label.

The distribution of prescription numbers by age band and percentage of off-label and unlicensed status is shown in Figure 2. There were 5,844 prescriptions for newborn babies outside of the

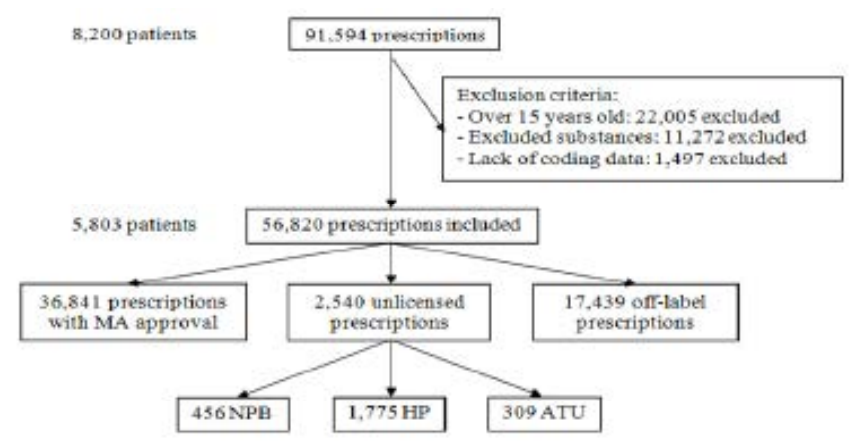

Figure 1. Inclusion criteria for prescriptions in the analysis.

MA: Marketing authorisation; ATU: Temporary authorisation for use; HP: Hospital preparation; NPB: Named patient basis pharmacy preparation.

Table 2. Demogratic data, hospital stays and prescriptions for patients included in the analysis ( $\mathrm{N}=5,803$ patients).

\begin{tabular}{|l|c|c|c|}
\hline & Min & Med & Max \\
\hline Age & 0 days & 19.6 months & 15.0 years \\
\hline Weight $(\mathrm{kg})$ & 0.7 & 11.0 & 144.0 \\
\hline Number of stays per patient & 1 & 1 & 16 \\
\hline Number of prescriptions per patient & 1 & 4 & 466 \\
\hline
\end{tabular}

Min: Minimum; Med: Median; Max: Maximum

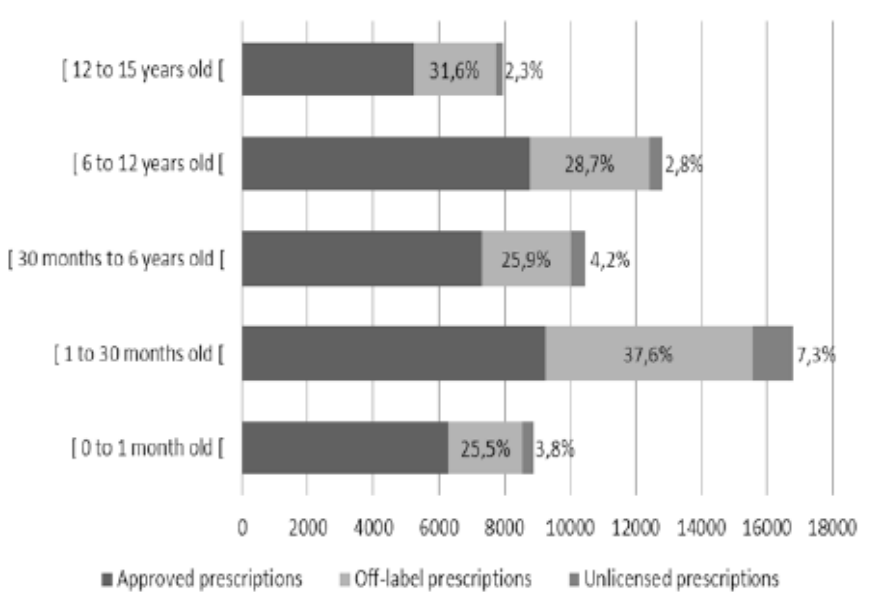

Figure 2. Distribution of prescriptions by age group and proportion of approved, off-label or unlicensed prescriptions $(\mathrm{N}=56,820)$.

MA: Marketing authorisation 
Delmas S (2016) Unlicensed and off-label medicines and prescriptions: A descriptive analysis of the medicines formulary and of the 56,800 prescriptions in a paediatric hospital

births service, $43.1 \%$ of which were off-label or unlicensed. A total of $53.6 \%$ of all patients $(3,111)$ received at least one off-label or unlicensed prescription. Broken down by status, $52.1 \%(3,026)$ of patients received at least one off-label prescription and $11.0 \%$ (637) received at least one unlicensed prescription. The distribution of medicines in the formulary and prescriptions by commercial status, paediatric status, pharmaceutical form and route of administration are show in Table 3.

Table 4 shows the distribution of medicines and prescriptions by ATC class. The proportion of medicines without PI or AL in the formulary is shown, together with off-label or unlicensed prescriptions. Figure 3 shows the proportion of off-label or unlicensed prescriptions in the ten highest prescribing departments. The three departments with the most patient hospital stays were births department, with 1,362 stays (18.3\%), orthopaedics, with 811 stays (10.9\%), and haematology department, with 706 stays (9.5\%). Departments with the largest number of off-label or unlicensed prescriptions were haematology $(\mathrm{N}=4,137)$, neonatology $(\mathrm{N}=2,774)$ and nephrology $(\mathrm{N}=2,276)$ departments. Figure 4 shows the ten most widely prescribed medicines and the proportion of off-label or unlicensed prescriptions. Two of these medicines, Eupantol ${ }^{\mathbb{R}} 40 \mathrm{mg}$ injectable solution and Speciafoldine ${ }^{\mathbb{R}}$ $5 \mathrm{mg}$ tablets are not approved for paediatric use. The ten medicines accounting for the largest number of off-label prescriptions (Figure 5).

Six hundred and one (66.3\%) of the 906 formulary medicines intended for oral use were inappropriate for children under six years old. Of the 17,668 prescriptions of medicines intended for oral use in children under six years old, $2,665(15.1 \%)$ were inappropriate pharmaceutical forms. Folic acid $5 \mathrm{mg}$ tablets (Speciafoldine ${ }^{\circledR}$ ) and folic acid AP-HP $2.5 \mathrm{mg}$ capsules (indicated for use in macrocytic anaemia due to folic acid deficiency in infants, a medicine reserved for hospital use, prescription of which cannot be devolved) made up for 744 prescriptions, nifepidine $5 \mathrm{mg}$ prolonged release capsules (named patient basis pharmacy preparation), 150 prescriptions, and Cortancyl ${ }^{\mathbb{R}}$ $5 \mathrm{mg}, 107$ prescriptions issued for children under six years old.

\section{Discussion}

This study provides a complete description of prescriptions describing the off-label and unlicensed use of medicines in a French paediatric university hospital. It also describes the medicines available in the treatment formulary to prescribers.

\section{Formulary}

Few published studies have considered hospital formularies. Some however do describe the medicines available on the market for the paediatric population. ${ }^{7}$ The only study to our knowledge which has examined the formulary of a paediatric hospital pharmacy was carried out in this hospital in 1999 [21]. The number of unlicensed medicines (ATU and HP) in our study is similar to the results of the previous analysis $(9.2 \%$, or 171 medicines compared to $9.5 \%$, or 163 medicines

Table 3. Commercial and paediatric status, pharmaceutical form and route of administration of medicines in the formulary $(\mathrm{N}=1,865)$ and prescriptions $(\mathrm{N}=56,820)$.

\begin{tabular}{|c|c|c|c|c|c|}
\hline \multirow{12}{*}{$\begin{array}{l}\text { Commercial status of } \\
\text { medicines and paediatric } \\
\text { status of medicines with MA }\end{array}$} & \multirow[b]{2}{*}{ MA } & \multicolumn{2}{|c|}{$\begin{array}{c}\text { Formulary } \\
(N=1,865)\end{array}$} & \multicolumn{2}{|c|}{$\begin{array}{c}\text { Prescriptions } \\
(\mathrm{N}=56,820)\end{array}$} \\
\hline & & $90.8 \%$ & (1 694) & $95.5 \%$ & $(54,280)$ \\
\hline & PI & $8.0 \%$ & $(149)$ & $20.8 \%$ & $(11,822)$ \\
\hline & $\mathrm{AL}$ & $47.1 \%$ & $(879)$ & $57.7 \%$ & $(32,762)$ \\
\hline & $\mathrm{CI}$ & $8.2 \%$ & $(153)$ & $3.3 \%$ & $(1,899)$ \\
\hline & RA & $1.0 \%$ & (19) & $0.3 \%$ & $(159)$ \\
\hline & $\mathrm{AD}$ & $8.4 \%$ & $(157)$ & $5.0 \%$ & $(2,812)$ \\
\hline & AI & $4.2 \%$ & (79) & $1.3 \%$ & $(757)$ \\
\hline & $\mathrm{N}$ & $13.8 \%$ & $(258)$ & $7.2 \%$ & $(4,069)$ \\
\hline & ATU & $3.2 \%$ & $(60)$ & $0.5 \%$ & (309) \\
\hline & HP & $6.0 \%$ & $(111)$ & $3.1 \%$ & $(1,775)$ \\
\hline & NPB & -- & -- & $0.8 \%$ & $(456)$ \\
\hline \multirow{14}{*}{$\begin{array}{l}\text { Route of administration and } \\
\text { pharmaceutical form }\end{array}$} & Oral & $48.6 \%$ & $(906)$ & $46.9 \%$ & $(26,642)$ \\
\hline & Tablet & $26.1 \%$ & $(487)$ & $10.4 \%$ & $(5,920)$ \\
\hline & Capsule & $9.5 \%$ & $(177)$ & $4.4 \%$ & $(2,483)$ \\
\hline & Solution/suspension & $4.9 \%$ & (92) & $16.8 \%$ & $(9,564)$ \\
\hline & Powder & $2.6 \%$ & (48) & $6.1 \%$ & $(3,463)$ \\
\hline & Others $\dagger$ & $5.5 \%$ & $(102)$ & $9.2 \%$ & $(5,203)$ \\
\hline & Injectable & $38.7 \%$ & $(722)$ & $46.1 \%$ & $(26,174)$ \\
\hline & Solution & $26.1 \%$ & $(487)$ & $32.6 \%$ & $(18,532)$ \\
\hline & Powder & $10.0 \%$ & (186) & $12.5 \%$ & $(7,086)$ \\
\hline & Otherstt & $2.6 \%$ & (42) & $1.6 \%$ & $(900)$ \\
\hline & Cutaneous & $4.1 \%$ & (77) & $1.0 \%$ & $(568)$ \\
\hline & Ophthalmic & $2.5 \%$ & (46) & $0.8 \%$ & (463) \\
\hline & Respiratory & $2.1 \%$ & (40) & $4.0 \%$ & $(2,273)$ \\
\hline & Otherstti & $4.0 \%$ & (74) & $1.2 \%$ & $(700)$ \\
\hline
\end{tabular}

AD: Absence of paediatric data; AI: Absence of paediatric indication in monograph; MA: Marketing authorisation; ATU: Temporary authorisation for use; CI: Contraindicated

$<15$ years old; PI: Paediatric indication; AL: Indicated for use with age and/or weight limit; HP: Hospital preparation; NPB: Named patient basis pharmacy preparation; N:

No paediatric reference in the summary of product characteristics; RA: Reserved for adult use.

$\uparrow$ Suspensions, Granules, Syrups, Capsules, Gel, Gum, Paste.

$\dagger$ † Suspension, emulsion, implant.

††Rectal, oral, nasal, oracular, vaginal.

The percentages have been calculated with respect to the total number of medicines in the formulary or prescriptions. 
Delmas S (2016) Unlicensed and off-label medicines and prescriptions: A descriptive analysis of the medicines formulary and of the 56,800 prescriptions in a paediatric hospital

Table 4. Distribution of medicines and prescriptions by ATC class with proportion of medicines without PI or AL and off-label and unlicensed prescriptions

\begin{tabular}{|c|c|c|c|c|c|c|c|c|}
\hline \multirow{2}{*}{\begin{tabular}{|l|} 
ATC Class \\
N-Nervous system \\
\end{tabular}} & \multicolumn{2}{|c|}{$\begin{array}{c}\text { Proportion of medicines } \\
\text { in the formulary } \\
(N=1,865)\end{array}$} & \multicolumn{2}{|c|}{$\begin{array}{c}\text { Proportion of medicines } \\
\text { without PI or AL by } \\
\text { ATC class } \\
(\mathrm{N}=837)\end{array}$} & \multicolumn{2}{|c|}{$\begin{array}{c}\text { Proportion of prescriptions } \\
\qquad(\mathrm{N}=\mathbf{5 6 , 8 2 0})\end{array}$} & \multicolumn{2}{|c|}{$\begin{array}{l}\text { Proportion of off-label } \\
\text { prescriptions or medicines by } \\
\text { ATC class }(\mathrm{N}=\mathbf{2 0 , 0 1 0})\end{array}$} \\
\hline & $18.2 \%$ & $(339)$ & $44.8 \%$ & $(152)$ & $25.2 \%$ & $(14,313)$ & $22.3 \%$ & $(3,189)$ \\
\hline J-Anti-infectious & $17.4 \%$ & $(324)$ & $24.4 \%$ & (79) & $17.3 \%$ & $(9,816)$ & $19.3 \%$ & $(1,897)$ \\
\hline A-Gastrointestinal and metabolic system & $12.1 \%$ & $(225)$ & $42.7 \%$ & (96) & $22.4 \%$ & $(12,745)$ & $41.9 \%$ & $(5,336)$ \\
\hline B-Blood and haemopoietic organs & $10.0 \%$ & $(187)$ & $48.1 \%$ & (90) & $12.8 \%$ & $(7,297)$ & $49.0 \%$ & $(3,576)$ \\
\hline C-Cardiovascular system & $8.8 \%$ & $(164)$ & $71.3 \%$ & $(117)$ & $4.3 \%$ & $(2,435)$ & $77.2 \%$ & $(1,879)$ \\
\hline L-Antineoplastic and immunomodulating agents & $7.7 \%$ & $(143)$ & $51.0 \%$ & (73) & $3.1 \%$ & $(1,736)$ & $32.1 \%$ & $(557)$ \\
\hline H-Hormone system preparations & $4.2 \%$ & (79) & $41.8 \%$ & (33) & $4.0 \%$ & $(2,263)$ & $32.7 \%$ & $(741)$ \\
\hline V-Various & $3.5 \%$ & $(66)$ & $30.3 \%$ & $(20)$ & $0.9 \%$ & $(531)$ & $25.8 \%$ & $(137)$ \\
\hline R-Respiratory system & $3.3 \%$ & $(61)$ & $18.0 \%$ & (11) & $5.1 \%$ & $(2,890)$ & $29.0 \%$ & $(838)$ \\
\hline M-Musculoskeletal system & $3.2 \%$ & $(59)$ & $52.5 \%$ & (31) & $1.6 \%$ & $(918)$ & $50.1 \%$ & $(460)$ \\
\hline Others $\dagger$ & $11.7 \%$ & (218) & $61.9 \%$ & (135) & $3.3 \%$ & $(1,876)$ & $74.5 \%$ & $(1,400)$ \\
\hline
\end{tabular}

$†$ Dermatology, sensory organs, genitourinary system and sex hormones, anti-parasitic products, insecticides and repellents, no ATC class

MA: Marketing authorisation; ATC: Anatomical, therapeutic and chemical class

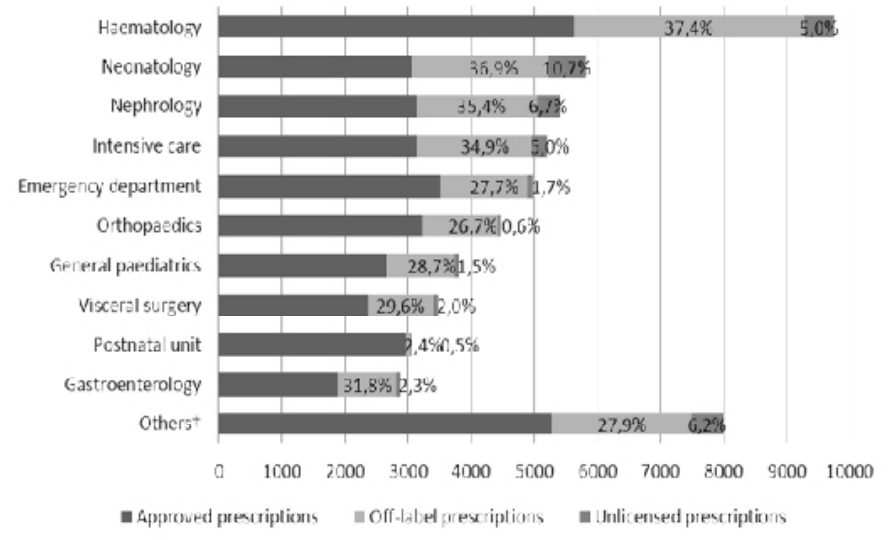

Figure 3. Distribution of prescriptions by department and proportion of approved prescriptions $(\mathrm{N}=56,820)$.

† Otorhinolaryngology (2,227 prescriptions; off-label: $19.7 \%$; unlicensed: $0.5 \%)$, Neurology $(1,977 ; 30.5 \% ; 11.1 \%)$, Surgery $(1,327 ; 34.8 \% ; 1.2 \%)$, Psychiatry $(892$; $23.7 \% ; 6.4 \%$ ), Cardiology $(866 ; 32.8 \% ; 18.1 \%)$, Endocrinology $(503 ; 30.2 \% ; 5.0 \%$ ), Ophthalmology $(2 ; 50 \% ; 0 \%)$, Department not completed $(200 ; 41.0 \% ; 2.5 \%)$.

MA: Marketing authorisation.

in 1999) ( $\mathrm{p}=0.71$ ). Differences were found in terms of paediatric status: $55.1 \%$ of PI or AL medicines in our study compared to $43.7 \%$ in the previous study $(\mathrm{p}<0.01) ; 8.4 \%$ of $\mathrm{AD}$ medicines compared to $3.6 \%$ $(\mathrm{p}<0.01)$, but particularly, $13.8 \%$ of medicines without paediatric information compared to $35.0 \%(\mathrm{p}<0.01)$. This may be explained by changes in the formulary or updates in the MA, the creation of a new category, AI, and the use of different data sources (Thériaque ${ }^{\circledR}$ compared to Vidal ${ }^{\circledR}$ ).

\section{Prescriptions}

Considerable variability is seen in off-label and unlicensed prescription and is due to several factors including the definition used for off-label and unlicensed, reference source(s) used, country, facility, proprietary product and age group examined $[9,22]$.

The definition of unlicensed medicines and off-label prescriptions varies between studies. The unlicensed prescription rate found in a Brazilian hospital was $11.8 \%$ compared to $4.5 \%$ in our study as CI

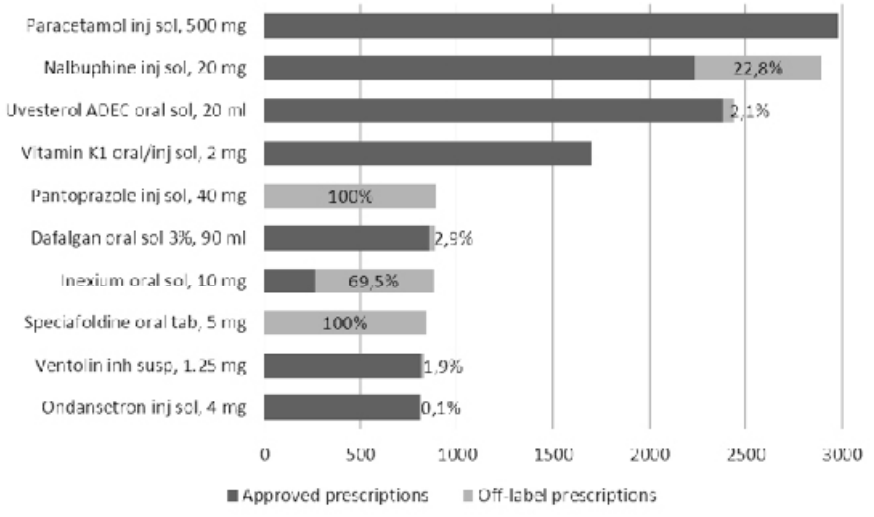

Figure 4. Number of prescriptions for the ten most widely prescribed medicines and proportion of approved prescriptions and off-label prescriptions ( $\mathrm{N}=15$ 129).

MA: Marketing authorisation; Tab: Tablet; Inh: Inhaled; Inj: Injectable; Oral: Oral; Sol: Solution; Susp: Suspension.

Equivalences between proprietary products/INN: Uvesterol/ vitamins A, D, E and C; Dafalgan/ paracetamol; Inexium/ esomeprazole; Speciafoldine/ folic acid; Ventolin/ Salbutamol.

medicines in children were classified as unlicensed [23]. In our study we adopted the definition used by Turner which has its limitations and appears to be inappropriate for some situations [11]. Some ATU relate to medicines $\left(\right.$ Syprol $^{\circledR}$, Capoten ${ }^{\circledR}$, PMS-Isoniazide ${ }^{\circledR}$ ) which have paediatric MA in other countries and are imported, as their pharmaceutical form is more suitable for paediatric practice than the tablets available in France. These may however be classified as unlicensed.

Prescribing practices also vary between countries. Many preparations in Netherlands hospitals are prepared from commercial presentations. This results in a larger number of unlicensed medicine prescriptions, figures ranging from $28 \%$ to $42 \%$ [10,22]. Only a limited number of named patient basis pharmacy preparations were issued in our study $(0.8 \%, \mathrm{~N}=456)$ and the number of unlicensed prescriptions was small $(4.5 \%, \mathrm{~N}=2,540)$. The Robert-Debré Hospital pharmacy however, prepares many parental nutrition and chemotherapy bags which have not been included in our analysis. 


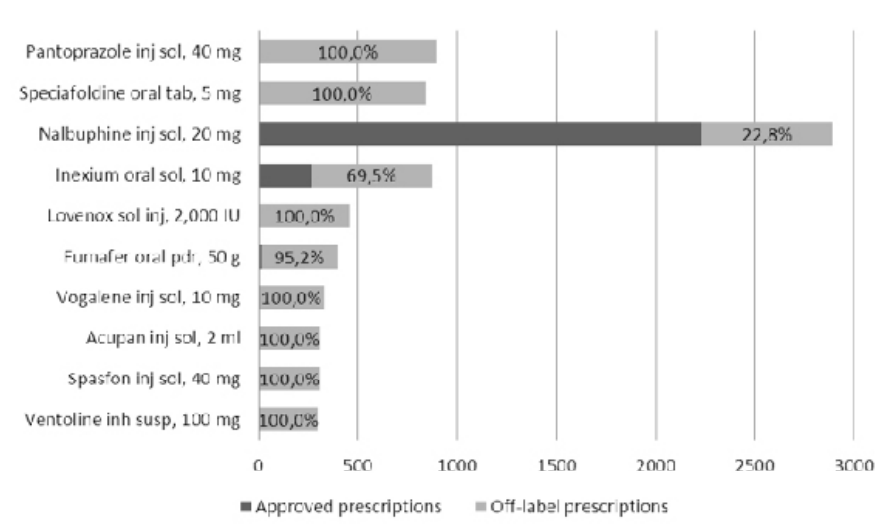

Figure 5. The most widely prescribed off-label medicines, total number of prescriptions and proportion of approved prescriptions and off-label prescriptions $(\mathrm{N}=7,612)$.

MA: Marketing authorisation; Sol: solution; Tab: Tablet; Inh: Inhaled; Inj: Injectable; Pdr: Powder; Oral: Oral; Susp: Suspension.

Equivalences between proprietary products/INN: Speciafoldine/ folic acid; Inexium/ esomeprazole; Lovenox/ enoxaparin; Fumafer/ ferrous fumarate; Vogalène/metopimazine; Acupan/ nefopam; Spasfon/ phloroglucinol; Ventolin/ Salbutamol.

The medical specialities considered and age bands studied result in different published percentage rates for off-label and unlicensed prescriptions. Neonatology intensive care units prescribe more offlabel and unlicensed prescriptions and the number of medicines with MA approval for the age group decreases with the age of the child [7,22, 25]. The off-label and unlicensed prescription rates in our study were, on first sight, however lower in newborn babies (29.3\%). This figure reflects very different practical realities: $64.5 \%$ of newborn babies' stays occur in the birth department, and this department had the lowest rate of off-label or unlicensed prescriptions at $2.9 \%$. However, the neonatology department, in which only $24.8 \%$ of newborn babies' stays occurred, accounted for more than half of the prescriptions in this population, and has a high rate of off-label or unlicensed prescriptions (47.6\%). This figure is lower than in most other studies (from $55 \%$ to $79 \%$ ), a difference which may be explained by the fact that we did not consider either the dosage, indication or route of administration in defining whether the prescription was approved under its MA [22].

Most of these off-label or unlicensed prescriptions are for infants (44.9\%) and prescriptions for newborn babies outside of the births service accounted for $43.1 \%$ of off-label or unlicensed prescriptions. This rate in higher child age groups ranged from $30.1 \%$ to $33.9 \%$ and is explained by the fact that many summaries of product characteristics (SPC) describe an indication or dosage for a child but not one for infants.

Although the percentage of off-label or unlicensed prescriptions is high, this does not necessarily reflect the extent of the phenomenon. The off-label or unlicensed prescription rate in the cardiology department (50.9\%) accounted for 441 off-label and unlicensed prescriptions and whilst the emergency department had a lower rate of $29.4 \%$, it accounted for 1,461 off-label or unlicensed prescriptions, i.e. approximately 3.3 times more than in cardiology.

The ten most widely used medicines account for over a quarter of prescriptions. Two of these do not have MA for paediatric use (Eupantol ${ }^{\circledR}$ and Speciafoldine ${ }^{\circledR}$ ). At the time the data were collected, injectable esomeprazole Inexium ${ }^{\circledR}$ did not yet have MA for children over one year old. Two other proprietary products had high off-label prescribing use: nalbuphine (659 unlicensed prescriptions), which is contraindicated in children under eighteen months old but is widely used in routine practice, and esomeprazole $10 \mathrm{mg}$ sachets (609 off-label prescriptions), which is not recommended for use in infants under a year old in the absence of available data. No proton pump inhibitor has MA approval for use under the age of one year old although these are widely prescribed for gastroesophageal reflux. The only treatments with MA approval in this situation are the antacids and local gastric agents, which are less effective.

Other medicines are widely used despite the fact that they do not have MA approval for paediatric use and no paediatric dosage is listed in the literature (for example nefopam, with 312 prescriptions, all off-label). Conversely, Uvesterol ADEC ${ }^{\circledR}$ is only indicated for use in newborn babies and infants and is sometimes prescribed for older children. It may be suspected that this is being substituted for Uvedose ${ }^{\mathbb{R}}$ in these patients.

\section{Comparison of the formulary with prescriptions}

To our knowledge, no studies have yet compared a hospital formulary to the prescriptions which are actually made in the hospital. Medicines which are unlicensed for paediatric use (neither PI nor AL) accounted for $44.9 \%$ (837) of the formulary although only for $21.5 \%$ $(12,268)$ of prescriptions. Medicines used in an ATU or HP are used less frequently than those with MA approval and accounted for $9.2 \%$ (171) of the formulary medicines but only $3.6 \%(2,084)$ of prescriptions.

We found that the percentage of off-label or unlicensed prescriptions of an ATC class was directly related to the percentages of PI and AL medicines available in the formulary. Cardiovascular system medicines accounted for $8.8 \%$ of proprietary products in the formulary and $4.3 \%$ of prescriptions. This had the highest off-label or unlicensed prescription rate of $77.2 \%$. We found 13 INN for beta blockers in the formulary, representing 32 medicines amongst which only acebutolol oral solution and propranolol injectable vial have MA approval from the age of 30 months onwards. The majority have no paediatric information in the SPC ( $\mathrm{N}=20$ medicines), some of which are not recommended in the absence of data or 'AD' $(\mathrm{N}=5)$, and only three are contraindicated in children. Examining the SPC for these three medicines we found that this contraindication is based not on any actual studies but because of a lack of data.

Despite the few appropriate oral presentations for children under six years old, only $8.5 \%$ or 3,051 prescriptions issued for this age band did not follow the recommendation not to administer a solid oral presentation under the age of six years old. This is most often due to a lack of appropriate presentation for children although some inconsistencies are also found: Cortancyl ${ }^{\circledR} 5 \mathrm{mg}$ tablets is given to children under six years old although Solupred ${ }^{\circledR}$ is available in solution and has MA from birth onwards. Many capsules are opened and mixed with patients' food (for example, $2.5 \mathrm{mg}$ folic acid capsule AP-HP ${ }^{\circledR}$ ). Some children, particularly those suffering from chronic disease, are able to swallow tablets under age of six years old and prefer them to multiple doses of liquid presentations.

Conversion of pharmaceutical products into appropriate forms for children by crushing, dissolving and dividing raises problems of stability, accuracy of dose administered and the bioavailability of these patient named and hospital preparations. Unpackaging and repackaging these medicines also increases the risk of errors. These unlicensed medicines are also poorly managed by health staff with, as a result, more prescribing, communication, dispensing and administration errors [25].

European legislation takes account of the medicines needs 
Delmas S (2016) Unlicensed and off-label medicines and prescriptions: A descriptive analysis of the medicines formulary and of the 56,800 prescriptions in a paediatric hospital

in paediatric use. Since 2007 it has been mandatory for any MA application in Europe to submit a PIP (paediatric investigation plan). It is possible to obtain PUMA (paediatric use MA) for medicines with MA in the public domain which is protected for ten years (eight years of intellectual property protection and two years of marketing protection). Pierre Fabre obtains MA for propranolol in haemangioma and will gain ten years of marketing protection for this use although propranolol is generic.

Off-label and unlicensed prescriptions are sometimes the best solution available in the absence of a treatment with MA. It is important to distinguish "well founded" off-label prescriptions based on expert opinions and the literature which have an ATU from "ill founded" prescriptions which are not based on scientific evidence, and whose merits are debatable [26].

Off-label prescriptions raise the problem of their efficacy and are also more commonly associated with adverse effects, particularly when the off-label use is of less relevance to the indication [22,27].

\section{Limitations}

Our analysis of prescriptions is based on a patient population under fifteen years old. The analysis of the formulary also includes medicines for hospitalised patients over fifteen years old and patients in gynaecology and obstetrics.

Our analysis of the formulary used the Theriaque ${ }^{\circledR}$ database whereas a previous study on the hospital pharmacy formulary used the Vidal ${ }^{\circledR}$ dictionary. Medicines with MA differ between countries and the databases provide different information. As there are few paediatric clinical studies there was a need for reliable common databases. Since 2007 the WHO has provided a reference standard for health professionals on alternate years - the "model list [...] of essential medicines intended for children" [28,29].

We defined off-label status for prescriptions only in terms of the patient's age and weight. We did not consider the indication, route of administration, dose or frequency as these data were not available for the analysis. Our study therefore tends to underestimate off-label prescribing as dosage and indication are common reasons for off-label prescribing [30].

Medicines prescribed for outpatients and chemotherapies were traced using a different software package and the data could not therefore be analysed.

\section{Conclusion}

Our study reflects six months of prescribing in a Paris mother's and children's university hospital with respect to medicines available in the hospital formulary. It is original as it examines in parallel those medicines which are available and the prescriptions which are issued. It has analysed a large number of prescriptions for hospitalised patients in sixteen different specialist departments. The unlicensed and off-label prescribing rates are as expected, high.

This study has enabled us to identify situations (department, age, medicine) which are more commonly associated with off-label prescribing. Off-label or unlicensed prescribing paediatric use raises a safety and efficacy problem for the treatments given. For this reason it is important to target situations, regulate these prescriptions and to produce reference standards which can be used in everyday practice by doctors in order to limit their use of these prescriptions.

\section{References}

1. Shirkey H (1968) Therapeutic orphans. J Pediatr 72: 119-120. [Crossref]

2. Christensen ML, Helms RA, Chesney RW (1999) Is pediatric labeling really necessary? Pediatrics 104: 593-597. [Crossref]

3. Nunn T, Williams J (2005) Formulation of medicines for children. Br J Clin Pharmacol 59: 674-676. [Crossref]

4. Pandolfini C, Bonati M (2008) European paediatric research and children's therapeutic needs. A trial review. Acta Paediatr 97: 1232-1237. [Crossref]

5. Ceci A, Felisi M, Baiardi P, Bonifazi F, Catapano M, et al. (2006) Medicines for children licensed by the European Medicines Agency (EMEA): the balance after 10 years. Eur J Clin Pharmacol 62: 947-952. [Crossref]

6. Masseron S, Fabreguettes A, Bourdon O (2006) Où est l'enfant dans l'innovation pharmaceutique? Journal de Pharmacie Clinique 25: 9-15.

7. Ragupathy R, Tordoff J, Norris P, Reith D (2010) Access to children's medicines in the United Kingdom, Australia and New Zealand in 1998, 2002 and 2007. Pharm World Sci 32: 386-393. [Crossref]

8. Conroy S, Choonara I, Impicciatore P, Mohn A, Arnell H, et al. (2000) Survey of unlicensed and off label drug use in paediatric wards in European countries. European Network for Drug Investigation in Children. BMJ 320: 79-82. [Crossref]

9. Lindell-Osuagwu L, Korhonen MJ, Saano S (2009) Off-label and unlicensed drug prescribing in three paediatric wards in Finland and review of the international literature. Journal of Clinical Pharmacy and Therapeutics 34: 277-287.

10. Jong GW, van der Linden PD, Bakker EM, van der Lely N, Eland IA, et al. (2002) Unlicensed and off-label drug use in a paediatric ward of a general hospital in the Netherlands. Eur J Clin Pharmacol 58: 293-297. [Crossref]

11. Turner S, Longworth A, Nunn AJ, Choonara I (1998) Unlicensed and off label drug use in paediatric wards: prospective study. $B M J 316: 343-345$. [Crossref]

12. Chalumeau M, Tréluyer JM, Salanave B, Assathiany R, Chéron G, et al. (2000) Off label and unlicensed drug use among French office based paediatricians. Arch Dis Child 83: 502-505. [Crossref]

13. McIntyre J, Conroy S, Avery A, Corns H, Choonara I (2000) Unlicensed and off label prescribing of drugs in general practice. Arch Dis Child 83: 498-501. [Crossref]

14. Lass J, Irs A, Pisarev H, Leinemann T, Lutsar I (2011) Off label use of prescription medicines in children in outpatient setting in Estonia is common. Pharmacoepidemiol Drug Saf 20: 474-481. [Crossref]

15. Schirm E, Tobi H, de Jong-van den Berg LT (2002) Unlicensed and off label drug use by children in the community: cross sectional study. BMJ 324: 1312-1313. [Crossref]

16. Horen B, Montastruc JL, Lapeyre-Mestre M (2002) Adverse drug reactions and offlabel drug use in paediatric outpatients. Br J Clin Pharmacol 54: 665-670. [Crossref]

17. Neubert A, Dormann H, Weiss J, Egger T, Criegee-Rieck M, et al. (2004) The impact of unlicensed and off-label drug use on adverse drug reactions in paediatric patients. Drug Saf 27: 1059-1067. [Crossref]

18. Mason J, Pirmohamed M, Nunn T (2012) Off-label and unlicensed medicine use and adverse drug reactions in children: a narrative review of the literature. Eur $J$ Clin Pharmacol 68: 21-28. [Crossref]

19. Turner S, Nunn AJ, Fielding K, Choonara I (1999) Adverse drug reactions to unlicensed and off-label drugs on paediatric wards: a prospective study. Acta Paediatr 88: $965-$ 968. [Crossref]

20. Centre national hospitalier d'information sur le médicament. Theriaque [Internet]

21. Combeau D, Fontan J-E, Brion F (1999) Analyse du livret thérapeutique d'un hôpital pédiatrique. Journal de Pharmacie Clinique 18: 5-10.

22. Cuzzolin L, Atzei A, Fanos V (2006) Off-label and unlicensed prescribing for new borns and children in different settings: a review of the literature and a consideration about drug safety. Expert Opin Drug Saf 5: 703-718. [Crossref]

23. Dos Santos L, Heineck I (2012) Drug utilization study in pediatric prescriptions of a university hospital in southern Brazil: off-label, unlicensed and high-alert medications. Farm Hosp 36:180-186.

24. Dell'Aera M, Gasbarro AR, Padovano M, Laforgia N, Capodiferro D, et al. (2007) Unlicensed and off-label use of medicines at a neonatology clinic in Italy. Pharm World Sci 29: 361-367. [Crossref] 
Delmas S (2016) Unlicensed and off-label medicines and prescriptions: A descriptive analysis of the medicines formulary and of the 56,800 prescriptions in a paediatric hospital

25. Conroy S1 (2011) Association between licence status and medication errors. Arch Dis Child 96: 305-306. [Crossref]

26. Gijsen R, Jochemsen H, van Dijk L, Caspers P (2009) Frequency of ill-founded offlabel prescribing in Dutch general practice. Pharmacoepidemiol Drug Saf 18: 84-91. [Crossref]

27. Evidence of harm from Off-label use -2004 [Internet]. Accessed November 2014
28. CNHIM. Limite des classes d'âge au niveau français et européen. Accessed November 2014.

29. WHO | WHO Model Lists of Essential Medicines [Internet]. WHO. Accessed November 2014.

30. Pandolfini C, Bonati M (2005) A literature review on off-label drug use in children. Eur J Pediatr 164: 552-558. [Crossref]

Copyright: ( 2016 Delmas S. This is an open-access article distributed under the terms of the Creative Commons Attribution License, which permits unrestricted use, distribution, and reproduction in any medium, provided the original author and source are credited. 